\title{
Glyphosate and adverse pregnancy outcomes, a systematic review of observational studies
}

\author{
Jessica S. A. de Araujo ${ }^{1}$, Isabella F. Delgado ${ }^{1}$ and Francisco J. R. Paumgartten ${ }^{2 *}$
}

\begin{abstract}
Background: A study in frog and chicken embryos, and reports of a high incidence of birth defects in regions of intensive GM-soy planting have raised concerns on the teratogenic potential of glyphosate-based herbicides. These public concerns prompted us to conduct a systematic review of the epidemiological studies testing hypotheses of associations between glyphosate exposure and adverse pregnancy outcomes including birth defects.

Methods: A systematic and comprehensive literature search was performed in MEDLINE, TOXLINE, Bireme-BVS and SCOPUS databases using different combinations of exposure and outcome terms. A case-control study on the association between pesticides and congenital malformations in areas of extensive GM soy crops in South America, and reports on the occurrence of birth defects in these regions were reviewed as well.

Results: The search found ten studies testing associations between glyphosate and birth defects, abortions, pre-term deliveries, small for gestational date births, childhood diseases or altered sex ratios. Two additional studies examined changes of time-to-pregnancy in glyphosate-exposed populations. Except for an excess of Attention Deficit Hyperactivity Disorder - ADHD (OR = 3.6, 1.3-9.6) among children born to glyphosate appliers, no significant associations between this herbicide and adverse pregnancy outcomes were described. Evidence that in South American regions of intensive GM-soy planting incidence of birth defects is high remains elusive.

Conclusions: Current epidemiological evidence, albeit limited to a few studies using non-quantitative and indirect estimates and dichotomous analysis of exposures, does not lend support to public concerns that glyphosate-based pesticides might pose developmental risks to the unborn child. Nonetheless, owing to methodological limitations of existing analytical observational studies, and particularly to a lack of a direct measurement (urine and/or blood levels), or an indirect estimation of exposure that has proven valid, these negative findings cannot be taken as definitive evidence that GLY, at current levels of occupational and environmental exposures, brings no risk for human development and reproduction.
\end{abstract}

Keywords: Attention deficit hyperactivity disorder, Pesticides, Birth defects, Congenital anomalies, Abortion, Teratogenicity, Reproductive toxicity, Occupational exposure, Agricultural workers, Fecundity

\footnotetext{
* Correspondence: paum@ensp.fiocruz.br

${ }^{2}$ National School of Public Health, Oswaldo Cruz Foundation - FIOCRUZ, Av.

Brasil 4036, EXCAM building, rooms 101-104, 913, Rio de Janeiro, RJ

21040-361, Brazil

Full list of author information is available at the end of the article
} 


\section{Background}

Glyphosate ( $N$-(phosphonomethyl)glycine, GLY) is a broad-spectrum herbicide launched onto the market in 1974. It inhibits competitively the enzyme enolpyruvylshikimate phosphate synthase (EPSPS) thereby blocking the production of chorismate, an intermediate for the biosynthesis of phenylalanine, tyrosine and tryptophan [1]. Contrasting to plants, bacteria and fungi, animals do not have the genes coding for EPSPS and depend on a dietary source for these essential aromatic amino acids. Although exhibiting plant- selective toxicity, GLY-based herbicides might eventually impair human health through modes of action other than inhibition of a shikimate metabolic pathway [1].

Pre-marketing safety evaluation of GLY and its major breakdown product AMPA (aminomethylphosphonic acid) did not reveal substance-related significant health hazards. Some post-marketing toxicity studies conducted by academic researchers, however, raised concerns about possible adverse health consequences of occupational exposures to GLY-based herbicides [2-4]. A methodological constraint common to many of these non-industry toxicity studies is the use of a commercial product (e.g., Roundup ${ }^{\oplus}$ ) rather than the active ingredient (GLY), and the lack of adequate controls for the effects of formulation ingredients other than GLY. Formulated GLY-based herbicides often contain substantial amounts of surfactants (e.g., polyoxyethyleneamine or POEA) the biological effects of which may account for product toxicity.

Since the introduction of GLY-resistant genetically modified (GM) soybean in the 1990s, GLY has become the most extensively used herbicide in Brazil, USA and other major soybean production countries. Moreover, the ADI (Acceptable Daily Intake) for GLY established by FAO/WHO augmented from $0-0.3 \mathrm{mg} / \mathrm{kg} \mathrm{bw} / \mathrm{d}$ (1986) to $0-1.0 \mathrm{mg} / \mathrm{kg} \mathrm{bw/d} \mathrm{(2004),} \mathrm{while} \mathrm{maximum}$ residue concentrations (MRCs) for GLY in soy and several other food crops increased as well [5]. A recent classification of GLY as "probably carcinogenic to humans" (group 2A) by the IARC fueled the ongoing debate about the safety of this herbicide. Classification of GLY into 2A group was based on "limited" evidence in humans (association with non-Hodgkin lymphomas) and "sufficient" evidence of carcinogenicity in animals [6]. Because of IARC classification and growing public concerns on the safety of GLY, the Brazilian regulatory agency (ANVISA) has scheduled a re-evaluation of GLY-based herbicides for 2016.

Whether the extensive use of GLY poses a risk to human reproductive health is a controversial matter as well. Studies sponsored by pesticide manufacturers revealed no noticeable adverse effects of GLY on mammalian reproduction and prenatal development [1]. Nonetheless, in 2010, Paganelli et al. [4] described a harmful effect of GLY-based herbicides on the development of frog (Xenopus laevis) and chicken embryos. According to the authors, the neural crest was the primary target of GLY and the mode by which GLY disrupts embryo development would be similar to that of retinoic acid, a known potent human teratogen $[4,7]$. Along the same line, two experimental studies performed by independent researchers suggested that GLY might impair pre and postnatal development in rats $[2,3]$. Dallegrave et al. [2, 3] reported embryotoxic effects (delayed skeleton ossification in term fetuses) in the offspring of rats treated with a GLY-based herbicide during pregnancy, and a decreased sperm count in adult rats that had been exposed in utero and during lactation.

South America rural regions are particularly suitable for studies of GLY impact on human health. In Brazil, Paraguay and Argentina, there are large GM-soy crop areas and extensive use of GLY, while in Colombia and Equator attempts to eradicate illegal crops of coca and poppy involved aerial spraying of GLY-based herbicides [8]. A suspected increase in the incidence of birth defects in South American GM soy-crop areas has been cited in support to the notion that GLY might be a human developmental toxicant [4, 7, 9-11]. A putative teratogenicity of GLY has been often commented in the literature. Samsel and Seneff [12], for instance, speculated that GLY might play a role in the pathogenesis of celiac (and gluten intolerance) disease and proposed that adverse influence of maternal celiac disease and GLY on prenatal development might share a common mode of action.

This systematic review was undertaken to evaluate whether results from the existing epidemiological studies are consistent with the notion that maternal and/or paternal exposure to GLY increases the risk of birth defects and/or other adverse pregnancy outcomes.

\section{Methods \\ Literature sources and search strategy}

A search was conducted in MEDLINE, TOXLINE, BIREME/BVS (Health Virtual Library-Brasil / "Biblioteca Virtual em Saúde-Brasil") and SCOPUS electronic databases to identify studies on human reproductive and/or developmental outcomes and GLY-based pesticide exposures. The literature search covered time windows between the inception of the database and May 9th, 2015 (MEDLINE), May 12th, 2015 (BIREME/BVS), May 14th, 2015 (TOXLINE), and May 15th, 2015 (SCOPUS). The search in BIREME/ BVS database covered articles published in periodicals indexed in the Latin American and the Caribbean Literature on Health Sciences or LILACS ("Literatura LatinoAmericana e do Caribe em Ciências da Saúde"). LILACS, the most comprehensive index of scientific and technical literature on health of Latin America and the Caribbean, includes local journals not indexed in the other databases 
searched in this study. There was no restriction regarding the language of the article.

The search in all four databases combined a specific exposure term and one term related to the health outcomes of interest in English (i.e., "glyphosate AND developmental toxicity", "glyphosate AND birth defects", "glyphosate AND congenital anomalies", "glyphosate AND embryotoxicity", "glyphosate AND epidemiology", "glyphosate AND pregnancy", "glyphosate AND teratogenicity", "glyphosate AND reproductive outcomes", "glyphosate and abortions", "glyphosate AND malformations", glyphosate AND pregnancy outcomes", "Round up AND developmental toxicity", "Round up AND birth defects", "Round up AND congenital anomalies", "Round up AND embryotoxicity", "Round up AND epidemiology", "Round up AND pregnancy", "Round up AND teratogenicity", "Round up AND reproductive outcomes", "Round up and abortions", "Round up AND malformations", "Round up AND pregnancy outcomes". To ensure the completeness of the search, the reviewers cross checked reference lists in the selected articles and reviews on this topic to identify by hand searches any relevant studies that might have been eventually missed by the electronic search.

\section{Study selection and data extraction}

To be included in the review an observational study had to investigate whether paternal and/or maternal exposures to GLY before conception and/or during pregnancy increased risks of adverse pregnancy outcomes, childhood health disorders and/or changes in fecundability. Predetermined study criteria for exclusion were as follows: 1 ) in vitro experimental studies, 2) in vivo and ex vivo studies in animals, 2) studies of effects on non-target species other than humans, 3) studies in the area of pesticide chemistry and agricultural sciences, 4) report of clinical cases, series of cases, and treatment of intoxications, 5) studies of associations of postnatal exposures with nondevelopmental and/or non-reproductive health outcomes, 6) letters, reviews, editorials, reports, comments, documents issued by regulatory bodies, and book chapters.

The selection of studies for reviewing involved a twophase screening process: at first publications were screened by titles and abstracts, and if deemed potentially relevant, at a subsequent phase, full text articles were retrieved. Screening of records for study eligibility was conducted independently by two reviewers (JAA and FJRP). If a disagreement persisted after being extensively discussed by the two reviewers, a third investigator (IFD) was asked to resolve it. For the qualitative synthesis the following data were extracted from the selected articles: study type, the studied population, its size, location and time, how exposure to GLY was assessed, the adverse outcome of pregnancy and/or the reproductive outcome evaluated, whether or not the outcome was significantly associated with GLY, and the strength of association (e.g. OR) if available.

\section{Results}

After excluding all duplicates, the total number of documents retrieved by our search on multiple electronic databases was 260 . Six additional articles potentially eligible were identified through hand-searches. Of these 266 records, 251 documents were excluded by their titles and abstracts. Most epidemiologic studies found by the search in electronic databases investigated whether paternal and/or maternal exposure to multiple pesticides (including GLY) was associated with a higher risk of decreased fecundity, miscarriages and congenital malformations and/or functional disorders in the progeny. Only the studies testing whether GLY-based herbicides were associated with altered fecundity and/or adverse pregnancy outcomes were eligible for review. As shown in the flowchart depicted in Fig. 1, 3 out of 15 full-text articles assessed for eligibility were excluded and the reasons for their ineligibility are informed in Table 1 . Seven out of the 12 remaining studies addressed the question as to whether parental exposures to GLY increased risks of birth defects and/or childhood functional disorders in the offspring (Table 2), while the other five studies investigated potential effects of exposure to this herbicide on time-to-pregnancy, pre-term deliveries, small-forgestational-age births and pregnancy losses (Table 3).

\section{Birth defects and childhood diseases in the progeny}

A case-control study by Garcia et al. [13] investigated whether father exposure to pesticides increased the risk of birth defects. Garcia et al's study considered only congenital anomalies or groups of defects with a high prevalence at birth. Controls were non-malformed live-born babies matched (1:1) with the cases by hospital and date of birth. Individual exposures were assessed by interviewing (questionnaire) fathers and mothers for involvement in activities potentially related to pesticide exposure. The risk period for exposure was defined as 3 months before conception or during the 1st trimester or both for the father and during the 1st month preceding conception and the 1st trimester or both for the mother. Risk estimates were calculated for all birth defects jointly. Dichotomous (exposed/ not exposed) data analysis revealed a positive association between exposure to pyridil derivatives and malformations (adjusted OR, $95 \%$ CI, 2.77, 1.19-6.44), whereas no association between GLY (0.94, 0.37-2.34) and other pesticides with congenital anomalies was detected.

Rull et al. [14] pooled data from two case-control study populations of infants with Neural Tube Closure Defects (NTD) and non-malformed controls (California, US, 1987-1991) to investigate whether maternal 


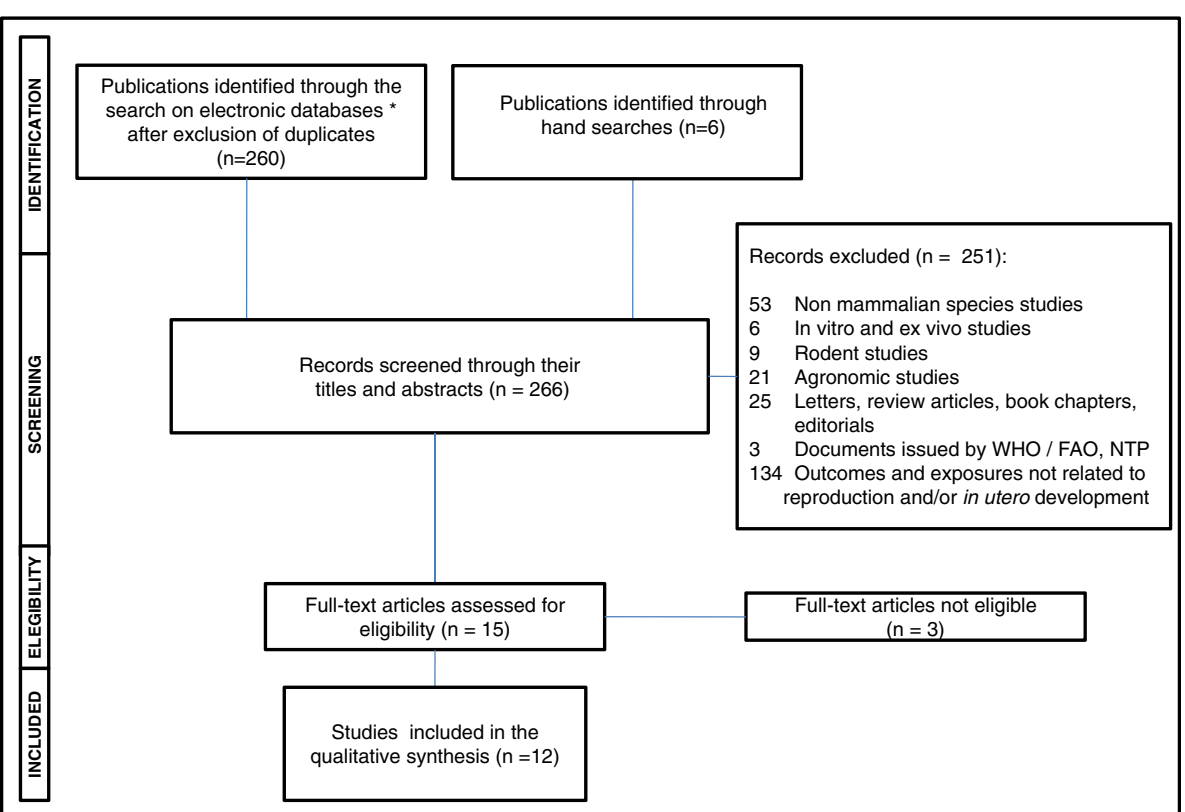

Fig. 1 Flowchart of selection of observational studies for inclusion in the systematic review. *MEDLINE, TOXLINE, Bireme/BVS and SCOPUS

Table 1 Characteristics of excluded studies (full text articles) and the reason for their ineligibility

\begin{tabular}{|c|c|c|c|c|}
\hline Study & $\begin{array}{l}\text { Study type, population and } \\
\text { location }\end{array}$ & Exposure assessment & Conclusions & Reason for ineligibility \\
\hline $\begin{array}{l}\text { Pogoda and Preston- } \\
\text { Martin, 1997. [35] }\end{array}$ & $\begin{array}{l}\text { Follow up to population- } \\
\text { based case-control study of } \\
\text { pediatric brain tumors in Los } \\
\text { Angeles county, CA, US, from } \\
1984 \text { through June } 1991 . \\
\text { Cases, } N=224 \text {, Controls, } \\
N=218 \text {. }\end{array}$ & $\begin{array}{l}\text { Household pesticide use } \\
\text { from pregnancy to diagnosis } \\
\text { assessed by phone } \\
\text { interviews. }\end{array}$ & $\begin{array}{l}\text { Risk was elevated for flea-tick } \\
\text { pesticides, } \mathrm{OR}=1.7,1.1-2.6\end{array}$ & $\begin{array}{l}\text { Round up was listed among } \\
\text { pesticides (herbicides) used } \\
\text { in law-garden. However, only } \\
\text { associations between broad } \\
\text { classes of pesticides and the } \\
\text { outcome (brain tumors) were } \\
\text { tested. Exposure assessment } \\
\text { encompassed both pre and } \\
\text { postnatal development and } \\
\text { did not discriminate between } \\
\text { the two periods. }\end{array}$ \\
\hline Larsen et al., 1998. [36] & $\begin{array}{l}\text { Retrospective study of time- } \\
\text { to-pregnancy (fecundability) } \\
\text { among Danish farmers ( } N= \\
1146) \text {. Telephone interviews } \\
\text { on time-to-pregnancy (How } \\
\text { many months did it take } \\
\text { your wife to get pregnant?) } \\
\text { and reproductive history }\end{array}$ & $\begin{array}{l}\text { Exposure data obtained by } \\
\text { phone interviews (use of } \\
\text { pesticides the year before } \\
\text { the youngest child was } \\
\text { born). Exposed groups: } \\
\text { traditional farmers, traditional } \\
\text { farmers who did not spray } \\
\text { pesticides themselves, } \\
\text { organic farmers. }\end{array}$ & $\begin{array}{l}\text { Fecundability ratio between } \\
\text { "traditional farmers who } \\
\text { applied pesticides" and } \\
\text { "organic farmers": } 1.3 \text {, } \\
0.75 \text { - } 1.40 \text {. }\end{array}$ & $\begin{array}{l}\text { Although GLY is mentioned } \\
\text { in the Introduction section, } \\
\text { authors did not investigate } \\
\text { whether 'time-to-pregnancy" } \\
\text { was altered specifically by } \\
\text { this herbicide. The authors } \\
\text { tested only classes of } \\
\text { "pesticides". }\end{array}$ \\
\hline Nevison 2014. [37] & $\begin{array}{l}\text { Ecological-type study design. } \\
\text { Temporal trends (1970-2005) } \\
\text { in autism compared to } \\
\text { temporal trends in US } \\
\text { application of GLY. Autism } \\
\text { counts were from the } \\
\text { Individuals with Disabilities } \\
\text { Education Act (IDEA) } \\
\text { database for } 50 \text { US states } \\
\text { plus District of Columbia. }\end{array}$ & $\begin{array}{l}\text { GLY exposure data were } \\
\text { aggregated at the group } \\
\text { level. Data were from US } \\
\text { department of agriculture. }\end{array}$ & $\begin{array}{l}\text { Increasing trends in } \\
\text { application of GLY positively } \\
\text { correlated to a marked rise in } \\
\text { autism prevalence in the US. }\end{array}$ & $\begin{array}{l}\text { In this study of temporal } \\
\text { trends, data on potential } \\
\text { exposure were aggregated at } \\
\text { the whole US population } \\
\text { level and encompasses } \\
\text { preconception, pre-natal and } \\
\text { postnatal periods of develop- } \\
\text { ment. Moreover, the eco- } \\
\text { logical study design leaves } \\
\text { the door wide open for non- } \\
\text { causal explanations for the } \\
\text { observed parallel rise in } \\
\text { temporal trends in GLY use } \\
\text { and autism prevalence. }\end{array}$ \\
\hline
\end{tabular}


Table 2 Studies of parental exposures to glyphosate and birth defects or functional disorders in the progeny

\begin{tabular}{|c|c|c|c|c|}
\hline Study & $\begin{array}{l}\text { Study type, population and } \\
\text { location }\end{array}$ & Exposure assessment & Adverse pregnancy outcome & $\begin{array}{l}\text { Association with GLY - } \\
\text { Statistical Analysis OR (CI } 95 \%)\end{array}$ \\
\hline \multirow{2}{*}{$\begin{array}{l}\text { Garcia et al., } \\
1998 \text { [13] }\end{array}$} & \multirow{2}{*}{$\begin{array}{l}\text { Case-control study with } 261 \\
\text { matched pairs in } 8 \text { hospitals of } \\
\text { Comunidad Valenciana, Spain. }\end{array}$} & \multirow{2}{*}{$\begin{array}{l}\text { Paternal exposure. Fathers were } \\
\text { interviewed for obtaining } \\
\text { detailed information on direct } \\
\text { involvement in handling of } \\
\text { pesticides. }\end{array}$} & \multirow{2}{*}{ Congenial malformation (any) } & $1.23(0.59-2.56)$ crude \\
\hline & & & & $0.94(0.37-2.34)$ adjusted \\
\hline $\begin{array}{l}\text { Rull et al., } 2006 \\
\text { [14] }\end{array}$ & $\begin{array}{l}\text { Case-control study. Rural } \\
\text { California US population }\end{array}$ & $\begin{array}{l}\text { Maternal residential proximity } \\
(<1,000 \mathrm{~m}) \text { to pesticide sprayed }\end{array}$ & $\mathrm{NTD}^{\mathrm{a}}$ & $\begin{array}{l}\text { Conventional logistic } \\
\text { regression models }\end{array}$ \\
\hline
\end{tabular}

[14] California US population (California Birth Defects Monitoring Program) -19871991 (pooled data of 2 casecontrol studies) $)^{\mathrm{b}}$. Controls: unmatched randomly sampled from all live born in the same sampling time without congenital anomalies diagnosed before the 1st birthday.

Yang et al., 2014 [16]

Carmichael et al., 2013 [15]

Shaw et al 2014 [17] by the CA Birth Defects
Case-control study. CA Birth Defects Monitoring Program, 1997-2006. San Joaquin Valley CA US. Cases ( $n=763)$ : infants/ fetuses with anencephaly or spina bifida and those with cleft palate (CP) or cleft lip (CL) with or without CP. Diagnoses confirmed by clinical geneticists. Cases suspected to having singe-gene conditions, chromosome abnormalities and an identified syndrome were not eligible. Controls $(n=$ 974) non-malformed live-born infants selected at random from birth hospitals.

Case-control study. Study population was all male infants born from 1991-2004 to mothers who were residents of 8 CA Central Valley counties. Cases $(n=690)$ were infants with hypospadias ascertained Monitoring Program (19912004); Controls $(n=2195)$ were live-born male infants with no major malformation selected randomly from the birth population $(n=2195)$.

Case-control study. Study population was from the San Joaquim Valley of California, US (1997-2006). Cases were 156 infants/fetuses were infants with gastroschisis confirmed by clinical geneticists and the controls $(n=785)$ were nonmalformed live-born infants randomly selected from birth hospitals to represent the population from which the cases arose Cases with recognized or suspected to have single-gene conditions or chromosomal abnormalities or

1.5 (1.0-2.4)-Single pesticide 1.5 (0.8-2.9)-Multiple pesticides

位e (residential addresses 2 weeks or more during the periconceptional period linked to geographic distribution of crops; pesticide use reports)

Maternal residential proximity to pesticide sprayed crops during periconceptional period (time window of exposure: 1 month before to 2 monthsnths after reported date of conception) (computerbased questionnaire administered primarily by telephone 6 weeks to 24 months after the date of infant delivery). Mothers with diabetes were excluded.

Maternal residential proximity (within a $500 \mathrm{~m}$ radius) to pesticide sprayed crops during early pregnancy (1-98 days after reported date of conception; 1-14 weeks embryonic age) /questionnaire. Birth certificate accession numbers were used to request access to maternal residential addresses at delivery. Data on pesticide applications (Pesticide Use Reporting records) were from the CA department of pesticide regulation.

Residential proximity (within $500 \mathrm{~m}$ radius) to pesticide applications (to estimate pesticide applications data were obtained from Pesticide Reporting Records from the California Dept of Pesticide Regulation). Maternal interviews (by phone) using a standardized computer-based questionnaire took place between 6 weeks and 24 months after infant's estimated date of delivery. Mothers reported residential history from 3 month before
Hypospadias

Gastroschisis

0.9 (0.6-1.4) - crude OR

0.9 (0.6-1.5) - adjusted OR
0.68 (0.34-1.37) - lowest (total amount applied $<1.22 \mathrm{lb}$ )

0.44 (0.19-1.01) - intermediate (total-amount applied 1.22-6.92 lb).

0.88 (0.48-1.64) - highest (total amount applied $\geq 6.93 \mathrm{lb}$ ). 
Table 2 Studies of parental exposures to glyphosate and birth defects or functional disorders in the progeny (Continued)

\begin{tabular}{|c|c|c|c|c|}
\hline & $\begin{array}{l}\text { with identifiable syndromes } \\
\text { were ineligible. Cases and } \\
\text { controls whose mothers had } \\
\text { diabetes were excluded from } \\
\text { analysis. }\end{array}$ & $\begin{array}{l}\text { conception through delivery, } \\
\text { including dates and residences } \\
\text { occupied for }>1 \text { month. Time } \\
\text { window of exposure analyzed } \\
\text { went from } 1 \text { month before to } \\
2 \text { months after the mother } \\
\text { reported date of conception. }\end{array}$ & & \\
\hline $\begin{array}{l}\text { Garry et al., } \\
2002 \text { [18] }\end{array}$ & $\begin{array}{l}\text { Cross-sectional study. Certified } \\
\text { pesticide appliers (licensed } \\
\text { between } 1991 \text { and 1996) in } \\
\text { Red River Valley, Minnesota US. } \\
\text { Participants randomly selected } \\
\text { were invited by phone } \\
\text { interview and asked to return a } \\
\text { detailed written questionnaire } \\
\text { on reproductive health and } \\
\text { pesticide use assessment. } \\
\text { Informants were at least one } \\
\text { member of } 695 \text { families ( } 228 \\
\text { male spouse applicators, } 90 \\
\text { female spouses, } 377 \text { couples). }\end{array}$ & $\begin{array}{l}\text { Each certified pesticide } \\
\text { applicator was interviewed by } \\
\text { phone on current and past use } \\
\text { of pesticides with attention to } \\
\text { product name, years used and } \\
\text { no. of days per year applied. } \\
\text { Approximately } 6 \text { months later } \\
\text { participants were interviewed } \\
\text { again by a written } \\
\text { questionnaire. Spouses were } \\
\text { also interviewed by phone and } \\
\text { again by written questionnaire. } \\
\text { Frequencies of the outcome } \\
\text { were compared between those } \\
\text { who reported the use of GLY } \\
\text { and those who did not report } \\
\text { the use. (dichotomous } \\
\text { pesticide exposure). }\end{array}$ & ADD/ADHD & $3.6(1.3-9.6)$ \\
\hline $\begin{array}{l}\text { Waselak et al. } \\
2007 \text { [19] }\end{array}$ & $\begin{array}{l}\text { Cross-sectional study. Farm } \\
\text { couples were from the Ontario } \\
\text { Farm Family Health Study } \\
\text { (OFFHS), a study designed to } \\
\text { retrospectively assess the } \\
\text { effects of pesticide exposures } \\
\text { on reproductive health. } \\
\text { Couples were eligible if they } \\
\text { were married or living as } \\
\text { married, living year-around on } \\
\text { a farm operation, and the wife } \\
\text { was at most } 44 \text { years of age. } \\
\text { Questionnaire were mailed to } \\
\text { each farm family to get } \\
\text { information on health status, } \\
\text { pesticide use and farm-activity } \\
\text { exposures. Farm wives were } \\
\text { asked to self-report if "the } \\
\text { doctor has ever told them" if } \\
\text { their child had had chronic } \\
\text { bronchitis or cough, asthma, } \\
\text { hayfever or allergies. }\end{array}$ & $\begin{array}{l}\text { Information on agricultural } \\
\text { chemicals used on the farm } 6 \\
\text { largest crops sown or } \\
\text { harvested in } 1991 \text { were } \\
\text { obtained through a } \\
\text { questionnaire addressed to the } \\
\text { farm operator. Information on } \\
\text { historical farm chemical used } \\
\text { was obtained by questionnaire. } \\
\text { Questionnaires addressed to } \\
\text { husband and wife asked } \\
\text { information pertaining to } \\
\text { chemical activities on the farm } \\
\text { and around the home. The } \\
\text { year and month of chemical } \\
\text { use was matched with months } \\
\text { and years leading up to and of } \\
\text { each pregnancy. Pesticide } \\
\text { exposures during the } \\
\text { pregnancy period (month of } \\
\text { conception until the month of } \\
\text { delivery) were considered in } \\
\text { the analysis of child health } \\
\text { outcomes. Unexposed } \\
\text { pregnancies were those with } \\
\text { no reported pesticide use } \\
\text { during the same period. } \\
\text { Analysis: ratios exposed cases } \\
\text { to total exposed to GLY. }\end{array}$ & $\begin{array}{l}\text { Persistent cough / bronchitis, } \\
\text { asthma, allergies }\end{array}$ & $\begin{array}{l}\text { Male and female offspring } \\
\text { combined (OR adjusted): } \\
\text { cough/ bronchitis } 0.71 \\
(021-2.35) \text { asthma } 0.82 \\
(0.35-1.90) \text { hayfever/ allergies } \\
0.98(0.46-2.10)\end{array}$ \\
\hline
\end{tabular}

GLY glyphosate, SGA Small for Gestational Age, CL cleft lip, CP cleft palate, NTD neural tube defect, TTP (Time-to-pregnancy) is defined as the duration that a couple waits from initiating attempts to conceive until conception occurs. TTP is used to calculate probability of conception or the fecundability odds ratio (fOR). NTD ${ }^{a}$ including elective termination of pregnancy, confirmed diagnosis of anencephaly, spina bifida cystica, craniorrhachischisis and iniencephaly. First study: children of women in most CA counties, Second study: all CA counties except LA, Ventura and Riverside. ADD/ADHD Attention Deficit Disorder/Attention Deficit Hyperactivity Disorder. Significant associations are highlighted marked in bold type

residential proximity (within $1000 \mathrm{~m}$ ) to pesticide application areas during early pregnancy would increase the risk of these birth defects. Results revealed a significant association between residential proximity to GLY application sites and NTD in the offspring when a singlepesticide model of conventional logistic regression analysis was used $(\mathrm{OR}=1.5 ; 1.0-2.4)$. The association of GLY with NTD, however, was not significant when a multiple-pesticide model was adopted in the logistic regression analysis $(\mathrm{OR}=1.5 ; 0.8-2.9)$.

Carmichael et al. [15] conducted a case-control study to evaluate whether maternal residential proximity 
Table 3 Studies of parental exposures to glyphosate and reproductive outcomes other than birth defects

\begin{tabular}{|c|c|c|}
\hline Study & $\begin{array}{l}\text { Study type, population and } \\
\text { location }\end{array}$ & Exposure assessment \\
\hline $\begin{array}{l}\text { Savitz et al., } 1997 \\
\text { [20] }\end{array}$ & $\begin{array}{l}\text { Retrospective cohort study. } \\
\text { Ontario Farm Family Health Study } \\
\text { (OFFHS), farms likely to be full- } \\
\text { time family-run operations were } \\
\text { selected based on } 1986 \text { Canadian } \\
\text { Census of Agriculture. Couples } \\
\text { were considered as eligible } \\
\text { (telephone interview) based on } \\
\text { residence on or near the farm- } \\
\text { year-round, and age of female } \\
\text { partner ( } \leq 44 \text { years old). Among } \\
1898 \text { farm couples with } \\
\text { completed questionnaires (from } \\
\text { farm operator, husband and wife), } \\
3984 \text { pregnancies were identified. }\end{array}$ & $\begin{array}{l}\text { Paternal exposure assessed by } \\
\text { questionnaire interview. Men } \\
\text { were asked about their farm } \\
\text { activities over the past } 5 \text { years. } \\
\text { Five activities were presumed to } \\
\text { involve direct pesticide exposure: } \\
\text { mixing or applying crop } \\
\text { herbicides, insecticides, and } \\
\text { fungicides, yard herbicides, } \\
\text { livestock chemicals and building } \\
\text { pesticides. Male partners engaged } \\
\text { in any activity associated with } \\
\text { direct pesticide exposure for } \\
\geq 1 \text { month in the time window of } \\
3 \text { months before conception to } \\
\text { the time of conception. }\end{array}$ \\
\hline $\begin{array}{l}\text { Curtis et al., } 1999 \\
\text { [21] }\end{array}$ & $\begin{array}{l}\text { Retrospective cohort study. } \\
\text { OFFHS - same as described } \\
\text { above. Only planned pregnancies } \\
\text { were selected for the analysis } \\
\text { regardless of the pregnancy } \\
\text { outcome. }\end{array}$ & $\begin{array}{l}\text { Paternal exposure assessed by } \\
\text { questionnaire interview. Pesticide } \\
\text { used on the farm (monthly use) } \\
\text { during the month trying to } \\
\text { conceive or at any time during } \\
\text { the prior } 2 \text { months to capture the } \\
\text { time dependent exposure interval } \\
\text { that may have affected } \\
\text { spermatogenesis ( } 64 \text { days). }\end{array}$ \\
\hline
\end{tabular}

Arbuckle et al., Retrospective cohort study. 2001 [22] OFFHS - same as described above

Sanin et al., 2009 Ecological-type study design. [23]

Sathyanarayana et al. 2010 [24] 2004-2005 Outcome was time to pregnancy evaluated by questionnaire interview (How many months have you having sexual intercourse before you became pregnant for the first time?) women were invited to participate if their first pregnancy during the last 5 years and did not take contraceptives the year before becoming pregnant. 2751 women were included in the analysis. 159 women who reported consultation with a physician for fertility problems were excluded from multiple regression and alternative models.

Multiple regression analysis of birth weight. Pesticide applicators and their spouses enrolled between 1993 and 1997, lowa and North Caroline US. (2246 women).
Paternal exposure assessed by questionnaire interview. Male farm activities in the period from 3 months prior to conception through the month of conception were assessed by questionnaire and evaluated in relation to miscarriages, pre-term delivery and SGA births.

Exposure measurement: Five regions of Colombia with different agricultural practices and presence or not of aerial spray for eradication of illicit crops with GLY

Exposure assessed by interview and questionnaire

Birth weight

Mean birth weight \pm SD: $3586 \pm$ $546 \mathrm{~g}$.

GLY-associated change in birth weight: $4 \mathrm{~g},-40$ to $+48 \mathrm{~g}$. (NS) 
Table 4 Incidence of congenital malformations in the Chaco province (La Leonesa-Las Palmas) between 1997 and 2009

\begin{tabular}{llll}
\hline $\begin{array}{l}\text { Year } \\
(12 \text { mo) }\end{array}$ & $\begin{array}{l}\text { Malformed infants } \\
\text { (hospital-based } \\
\text { records, N) }\end{array}$ & $\begin{array}{l}\text { Births in the region } \\
\text { (population-based } \\
\text { registry) (N) }\end{array}$ & $\begin{array}{l}\text { Birth defects rates } \\
\text { (/ 10,000 births) }\end{array}$ \\
\hline $1997-8$ & 46 & 24,030 & 19.1 \\
$2001-2$ & 60 & 21,339 & 28.1 \\
$2008-9$ & 186 & 21,808 & 85.3 \\
\hline
\end{tabular}

${ }^{a}$ Neonatology Department, Hospital Perrando, Resistencia, Chaco Province, Argentina. Data were from the report by the Water Pollutants Investigation Committee, Chaco Province, Argentina, 2010 [27]

(within $500 \mathrm{~m}$ radius) to agricultural pesticide application areas during early pregnancy (i.e., 1-14 weeks of embryonic age or 1-98 days of date of conception) was associated with an increased incidence of hypospadias in the offspring (data collected by the investigators refer to births occurring from 1991 to 2004 in 8 counties in CA, US). Carmichael et al's study found no association of most pesticides including GLY with increased risks of hypospadias (phosphonoglycine, highest dose group: OR $=0.88,0.48-1.64$ ).

Yang et al. [16] investigated whether maternal exposure to pesticides (including GLY) during periconceptional period (i.e., from 1 month before to 2 months after the estimated date of conception) increases the risks of NTDs and/or orofacial clefts in the progeny. Maternal exposure to pesticides was inferred from the residential proximity to sprayed crops assessed by a questionnaire. Case-control analysis (based on data from the US National Birth Defects Prevention Study, from 1997 to 2002) found no association between GLY (phosphonoglycine) and anencephaly $(\mathrm{OR}=0.9,0.5-1.9)$, spina bifida $(\mathrm{OR}=0.9,0.5-1.4)$, cleft lip with and without cleft palate $(\mathrm{OR}=0.9,0.7-1.3)$ and cleft palate alone (OR $=0.9,0.5-1.5)$.

Shaw et al. [17] conducted a case control study in a population derived from one of the regions of highest use of pesticide in the US (San Joaquin Valley - CA) to examine whether early gestational exposures to pesticides (including GLY) were associated with risk of gastroschisis. Exposure during early gestation was assessed by residential proximity (within $500 \mathrm{~m}$ radius) to GLY/ pesticide applications from one month before to 2 months after mother reported date of conception. The investigators found no association between gastroschisis and maternal exposure to GLY (adjusted OR $=0.9$ (0.6$1.5)$.

In addition to the foregoing studies on GLY and congenital malformations, three other studies investigated associations of prenatal exposures to GLY with postnatal functional disorders in the exposed offspring.

A cross-sectional study by Garry et al. [18] conducted in 1997-1998 examined the incidence of birth defects and sex ratios in children born to pesticide applicators
(695 families) living in the Red River Valley of Minnesota, US. The investigators employed a detailed questionnaire to assess parental exposure to pesticides and examined medical records and birth certificates to confirm parent-reported health information. Of 19 children with Attention Deficit Hyperactivity Disorder (ADD/ ADHD), 5 were excluded from the analysis because the male applicator was reported as not being the biological father. The investigators found that 6 out of the remaining 14 children (43\%) who had parent-reported ADD/ADHD were born to GLY or phosphonamine herbicide applicators $(\mathrm{OR}=3.6,95 \%$-CI, 1.35-9.65).

Weselak et al [19] used data from the Ontario Farm Family Health Study (OFFHS) to investigate whether exposure of farm couples to pesticides (including GLY) during pregnancy increases the risk of health problems in their offspring, including persistent cough or bronchitis, asthma, and allergies or hay fever. The authors found no association between GLY exposure during pregnancy and persistent cough or bronchitis (male and female offspring combined, adjusted OR, CI $95 \%, 0.71$, $0.21-2.35)$, asthma (0.82, 0.35-1.90), and hay fever and allergies $(0.98,0.46-2.10)$.

In summary, except for positive associations of parental exposure to GLY with ADD/ADHD [18] and NTD (single-pesticide model of logistic regression) [14], we found no other evidence suggesting that parental exposure to GLY before conception and/or during pregnancy increases the risk of birth defects and/or psychiatric or immune system disorders in the progeny.

\section{Miscarriages, pre-term deliveries, small-for-gestational- date births, and fecundability}

Three retrospective cohort studies based on data from OFFHS study were published in the late 1990s and early 2000s. The OFFHS study was designed to assess retrospectively the potential adverse effects of commonly used pesticides on pregnancy (Table 3).

Savitz et al [20] examined the effects of male partner self-reported exposure to pesticides (0 to 3 months prior to conception) on female partner miscarriages, pre-term deliveries and small for gestational age births (SGA). Among 1898 farm couples with completed questionnaires, 3984 pregnancies were identified. Of the included pregnancies, nearly $40 \%$ occurred 10 or more years before the interview, a long time interval that possibly enhanced the recall bias. Adjusted OR (CI $95 \%$ ) for GLY and miscarriages was $1.5(0.8-2.7)$ and $1.4(0.7-2.8)$ for crop and yard herbicides, respectively. No significant associations were found for GLY and pre-term deliveries (2.4, 0.8-7.9, crop), and GLY and SGA (0.8, 0.2-2.3, crop).

A study by Curtis et al [21], including only planned pregnancies $(N=2012)$, evaluated whether exposure to 
pesticides, assessed considering farm use and individual farm activities, was associated with a longer time-topregnancy. The results indicated that the use of GLY on the farm and pesticide activities reported by the husband, but not by the wife, was associated with a slightly increased fecundability (Conditional fecundability ratio; CFR, CI 95 \%, 1.30, 1.07-1.56). The authors found no other significant association between GLY and altered time-to-pregnancy. Overall, study results are consistent with the notion that exposure to GLY in farm activities did not impair fecundability.

A third study based on OFFHS data [22] found a significant association $(\mathrm{OR}=1.7,1.0-2.9)$ between parental pre-conception exposure to GLY and the risk of late abortions (12-19 weeks). The risk of early abortions, however, remained unaltered ( $<12$ weeks; OR $=1.1,0.7$ 1.9) if parents were exposed to GLY prior to conception. Post-conception exposure to GLY did not increase the risk of abortion at any gestational age $(\mathrm{OR}=1.1,0.7-1.7)$. A positive association between exposure to GLY before conception and late abortions is an unusual finding. Maternal and/or paternal preconception exposures are generally associated with early abortions (e.g., due to germ cell chromosomal abnormalities) while maternal exposures during pregnancy are most often associated with late abortions (e.g., due to harmful effects on the conceptuses).

An ecological-type study by Sanin et al [23] examined whether application of glyphosate by aerial spray for eradication of illicit crops (five Colombian departments, cross-sectional study, 2004-2005) was associated with prolonged time-to-pregnancy among fertile women living in sprayed areas. While data on the exposure to GLY were aggregated at the group level and place of residence is an inaccurate surrogate for degree of exposure, the study by Sanin et al (2009) showed no consistent association between aerial spray of GLY and longer average time-to-pregnancy in the population (Table 3).

Sathyanarayana et al [24] examined the association between maternal pesticide use and birth weight among women in the Agricultural Health Study (AHS), a large study of pesticide applicators and their spouses, enrolled between 1993 and 1997 in Iowa and North Caroline. The authors evaluated self-reported pesticide use of 27 active ingredients in relation to birth weight among 2246 women. Multiple regression estimates of change in birth weight (adjusted for site, maternal BMI, age, smoking, race, pre-term birth, medical parity) were obtained. Sathyanarayana et al found no association between birth weight and parental exposure to GLY (mean birth weight $=3586 \pm 546$ g; GLY-associated change in birth weight, $4 \mathrm{~g} ;-40$ to 48 ) (Table 3 ).

In summary, except for a positive association between parental pre-conception exposure to GLY and the risk of late abortions [22], studies included in this review revealed no evidence of increased risks of miscarriages, pre-term deliveries, small-for-gestational age births and impaired fecundability associated with occupational exposures to GLY-based herbicides before conception and/ or during pregnancy.

\section{Reports on the occurrence of birth defects in South America GM soybean crop areas}

Antoniou et al (2012) and others [9-11] cited two studies by South American researchers [24, 25] and one report from Chaco province (Argentina) health authorities in support of their statement that regulatory agencies have neglected the existing evidence suggesting that GLY might increase the risk of birth defects. The two studies were published in Spanish in South American medical journals [25, 26], while an English version of Chaco province report is available on the web [27]. None of these studies were identified by our search in electronic databases.

A case-control study by Benítez-Leite et al [25] found an increased rate of birth defects in neonates born to women exposed to unspecified pesticides during pregnancy. Although the article did not mention explicitly GLY-based herbicides, cases and controls came from a regional hospital in Itapúa Department (Paraguay) where GLY is extensively used in GM-soy crops. Conclusions from Benitez-Leite et al's investigation should be interpreted with caution due to study methodological weaknesses including 1) the lack of adequate control for selection and/or confounding bias, i.e., cases and controls were not matched according to a number of variables of interest (e.g., maternal age, use of medicines and others), nor were logistic regression and stratification used in the analysis of data; 2) an uncontrolled recall bias (mothers of malformed and healthy infants are known to remember differently past exposures); 3) the lack of detailed information on the applied questionnaire and on how interviewers were trained to avoid introducing an information bias (the interviewers were hospital internal doctors and nurses who were aware of the case or control status of the respondent); and 4) the inaccurate and dichotomous (Yes/No) assessment of pesticide exposure.

A cross-sectional study by Campaña et al. [26] reported the prevalence of 27 congenital anomalies in 7 geographic regions of Argentina including Cordoba and other provinces of intensive GM-soy planting and heavy use of GLY. The estimated prevalence of 27 birth defects in distinct regions was based on a sample of 21,844 malformed infants selected from a total of 855,220 births in 59 Argentinean hospitals of the ECLAMC (Latin American Collaborative Study on Congenital Malformations) network between 1997 and 2007. The estimated 
frequencies for 14 birth defects were higher in one or more regions when compared to the overall incidence for all 7 regions combined. For instance, the prevalence of spina bifida in Cordoba (CEN region, 12.2, 10.1-14.3) was somewhat higher than the overall prevalence in all regions combined (TOTAL, 9.9, 9.2-10.6). It was similar, however, to the prevalence of spina bifida in Buenos Aires metropolitan region (MET, 13.2, 11.8-14.7). The prevalence of anencephaly in Cordoba (CEN, 7.9, 6.39.8 ), on the other side, was similar to the prevalence estimated for all regions combined (TOTAL, 7.5, 6.9-8.1) and somewhat lower than the prevalence in Buenos Aires region (MET 10.3, 9.1-11.7). Overall, differences in the estimated prevalence of birth defects among regions were not consistent with the interpretation that there is an increased prevalence of NTDs and other congenital anomalies in Cordoba and/or in other regions of extensive use of GLY-based herbicides. It is of note that ECLAMC is a hospital-based (and not a population based) monitoring system, and thus regional frequencies estimated by Campaña et al. [26] do not necessarily reflect the prevalence of a birth defect in the population of the region. In addition to the foregoing, even if population based frequencies of some anomalies vary among regions, there exist many other possible explanations for inter-region differences including secular trends, altitude above sea level, folic acid fortification of wheat flour (introduced in Argentina in 2005, i.e., within the time period of study data gathering: 1997-2007), ethnicity, maternal age (not adjusted by authors' analysis) and a diversity of environmental factors and exposures.

An Investigation Committee commissioned by the government of Chaco province (Argentina) described a nearly three-fold increase in the incidence of birth defects in the region of La Leonese-Las Palmas during the last decade $[27,28]$. Since the apparent rise in the incidence of congenital anomalies paralleled a marked GMsoy crop expansion, the extensive use of GLY in the region has emerged as a suspected determinant factor [27, 28]. To estimate regional incidence rates, the Chaco province investigation committee divided the number of malformed newborns recorded by a single regional hospital (i.e., a hospital-based registry) by the overall number of births in the region (a population-based registry) for a given period of time (Table 4). While the overall number of births in the region remained fairly constant across the time period analysed (1997-2009), the number of malformed newborns recorded by the regional reference hospital dramatically increased in 2008/2009. Nonetheless, it is unclear whether the incidence of birth defects did in fact increase in the region since a hospital-based registry is not a reliable surrogate for a population-based registry of birth defects. Not only a number of births in the region may have occurred outside the regional hospital, but also the hospital may have received an undetermined number of pregnant women living outside the region of interest.

In summary, the Chaco province report [27], the case-control study by Benitez-Leite et al. [25] and the Campaña et al. [26] descriptive study do not lend support to the interpretation that the incidence of birth defects has increased in areas of extensive GM-soy plantations and GLY application.

\section{Discussion}

As previously commented, this review included only studies that provided results specific for GLY exposure and reproductive and developmental outcomes, that is, studies analyzing only whole classes of compounds such as pesticides and herbicides or other broad categories of active ingredients were ineligible for inclusion in the review.

This systematic review identified 7 observational studies addressing the question of whether pre-conception (paternal and/or maternal) and/or pregnancy (maternal) exposures to GLY increase risks of birth defects and/or childhood functional disorders in the offspring (Table 2). Moreover, we also reviewed 5 studies evaluating whether parental exposures to GLY increased risks of miscarriages, pre-term deliveries, SGA births and prolonged time-to-pregnancy (Table 3). None of the studies found significant associations of parental exposures to GLY with unspecified congenital malformations [13] or with specific birth defects such as gastrochisis [17], oral clefts [16] and hypospadias [15]. One study found a positive association of maternal residential proximity to GLY application sites with NTDs (with a single-pesticide model but not with a multiple pesticides logistic regression model) [14] while a further study [16] revealed no significant association of maternal exposure to GLY with NTDs. No positive associations of parental exposures to GLY with childhood allergies, asthma and bronchitis [19], longer time-to-pregnancy [21, 23], SGA births [20, 24], and pre-term deliveries [20] were reported either. Except for a significant association of pre-conceptional exposure to GLY with late abortions [22], no association of exposure to GLY with gestation losses was found [20, 22]. Overall, except for an excess of risk of ADD/ADHD among the offspring of GLY applicators reported by Garry et al. [18], analytical observational studies reviewed here led to the conclusion that exposures to GLY before conception and/or during pregnancy did not increase the risk of adverse reproductive outcomes.

The lack of association between maternal residential proximity to GLY-spraying areas and NTDs reported by Rull et al (with multiple pesticides logistic regression model) [14] and by Yang et al [16] is not consistent with Carrasco and others' hypothesis [4, 7] that events taking 
place during cephalic neural crest development would be the primary target for a putative GLY developmental toxicity. Paganelli et al's data [4] were obtained on frog and chicken embryos directed exposed to GLY-based herbicides and, as far as the authors are aware, no developmental toxicity study on mammalian species (rodents and lagomorph) has found an increased occurrence of NTDs in GLY exposed fetuses [1].

A major limitation common to all the foregoing studies was an inaccurate assessment of the exposure. In most studies shown in Tables 2 and 3 exposure to the herbicide was analyzed as a dichotomous (exposed / not exposed) variable, and the individual exposure status was inferred from responses to interviews and questionnaires. In one study (Table 3), an ecological-type design was used [23] and thus exposure data was aggregated at the group level as if all individuals living in the studied regions were evenly "exposed" or "not exposed" to GLY.

In fact, the individual exposure to GLY or any other pesticide depends on a number of factors such as wearing protective clothes, the diet, the amount of the pesticide used and others and varies within a population. The exposure or the internal dose received by members of a population is also a continuous variable. The dichotomization of this variable is likely to make analytical studies less sensitive to detect detrimental effects of GLY on health outcomes, if they do occur. For example, a number of individuals assigned to the "exposed group" might have received internal doses of GLY at levels below those (threshold) levels that would lead to adverse outcomes thereby diminishing the power of the study. Moreover, treating exposure as a binary variable precludes a further analysis of dose (concentration) - response relationship when a significant association is eventually found. As highlighted by Hill, a "biological gradient" or a "dose/ concentration-response relationship" is one of the aspects to be considered for ruling out possible non-causal explanations for the association [29].

In 4 out of 6 studies evaluating associations between exposure to GLY and the occurrence of birth defects or childhood functional disorders (Table 1), maternal "residential proximity" to GLY sprayed areas was used as a surrogate indicator of exposure to GLY. As far as the authors are aware, no bio-monitoring study has investigated the extent to which "residential proximity" is a valid and reliable non-quantitative indicator of increased exposure to GLY.

There exist only a few bio-monitoring studies on the human exposure to GLY. A bio-monitoring study by Acquavella et al [30] measured the levels of GLY in the 24-h urine samples of 48 farmers, their spouses and children, as part of the Farm Family Exposure Study in Minnesota US. Sixty percent of farmers, $4 \%$ of their spouses and $12 \%$ of their children had detectable levels of GLY in the urine on the day of pesticide application (geometric mean concentration was $3 \mathrm{ppb}$ and the maximum value was $233 \mathrm{ppb})$. The authors noted that farmers who did not use rubber gloves had urinary levels of GLY higher than the levels found among those who used this protective equipment (10 ppb versus $3 \mathrm{ppb}$ ). They also observed that all but one child with detectable levels of GLY had helped with the application or were present during pesticide mixing, loading or application [30].

A further study by Curwin et al [31] measured urinary levels of GLY and some other pesticides in farm and non-farm households (47 fathers, 48 mothers and 117 children) living in Iowa (US). Curwin et al's data demonstrated that detectable levels of GLY are present in the urine of most $(>60 \%)$ farm and non-farm US participants [31]. Moreover, detectable levels of GLY have also been found in the urine of farm and non-farm European residents by other bio-monitoring studies [32].

Two more studies published in scientific journals and three unpublished investigations reviewed by Niemann et al [32] also detected GLY in human urine samples. Taken together the seven bio-monitoring studies indicated that amounts of GLY in the ppb $(\mu \mathrm{g} / \mathrm{L})$ range are found in the urine of farm and non-farm individuals in the US and in the EU.

In addition to the foregoing studies on the levels of GLY in urine samples, there is a single study on the blood levels of GLY in pregnant women. Aris and Leblanc [33] measured concentrations of GLY in the blood serum of pregnant (maternal and fetal cord blood) and non-pregnant women from Eastern towns of Quebec, Canada. Participants reported not to have had any direct contact with pesticides and thus the diet remained as the most likely origin of GLY found in their blood. GLY was undetectable $(<15 \mathrm{ng} / \mathrm{mL})$ in the maternal and fetal cord blood $(n=30)$, and detected in only 2 out of 39 (5\%) non-pregnant women.

As aforementioned, bio-monitoring studies showed that GLY is detectable in the urine of farm and nonfarm individuals. Since soybeans and a variety of other food items may contain trace amounts of GLY, the diet is one of the possible sources of GLY residues found in the urine of farm and non-farm individuals. Occupational exposure through dermal route adds to this background ingestion of GLY residues.

According to Williams et al [1] estimates of exposure for aggregated acute and chronic exposure scenarios based on worst-case assumptions were 125 and $32.3 \mu \mathrm{g} /$ $\mathrm{kg}$ bw/day, respectively. For young children the estimated values were 97 and $52 \mu \mathrm{g} / \mathrm{kg}$ bw/day for acute and chronic exposures, respectively [1]. Based on the worst case assumptions, for an adult female applicator estimated dietary exposure would account for $23.8 \mu \mathrm{g} / \mathrm{kg}$ bw/day while occupational exposure would account for 
56.2 (acute) and $8.5 \mu \mathrm{g} / / \mathrm{kg}$ bw/day (chronic) exposures. For children aged 1 to 6 years, dietary exposure would account for $51.9 \mu \mathrm{g} / \mathrm{kg}$ bw/d while reentry and bystander exposures and some infrequent events would account for the additional exposure [1]. It is of note that for occupational exposure of applicators, according to Williams et al [1], the highest measured value from all biomonitoring studies was used for the "worst case" estimation of acute exposure. Since as a rule the monitoring studies were conducted on developed countries, the question arises as to whether the highest estimated values could be even higher in developing country scenarios where farmers do not routinely wear protective clothes and equipment.

Acquavella et al's study [31], for instance, demonstrated that, among farmers, the highest urinary levels of GLY were recorded on the day of application, and when protective gloves were not used during mixing, loading or spraying the herbicide. According to the authors, only $5 \%$ of farmers' spouses and $12 \%$ of their children had detectable levels of GLY in the urine, and all but one of the contaminated children had reported a direct contact with the herbicide product [31]. These findings raise doubts whether a mere residential proximity to cultivated areas does in fact add significantly to the background exposure to GLY that occurs through the diet irrespective of the individual place of residence.

\section{Conclusions}

In summary, except for a possible association with Attention Deficit Hyperactivity Disorder needing confirmation by further studies - data from existing epidemiologic studies do not lend support to the notion that GLY is a human reproductive and developmental toxicant. Nonetheless, this set of predominantly negative findings is far from providing a definitive evidence that occupational exposure to GLY poses no risk for human development and reproductive health. This systematic review found only a few studies on people occupationally exposed to GLY and, as a rule, the existing studies used non-quantitative estimations of exposure. Moreover, investigations on the potential adverse effects of GLY identified in the systematic review are heterogeneous regarding the developmental and reproductive outcomes studied. The variability in the outcomes investigated (e.g., one study on hypospadias, gastroschisis, and oral clefts, and two studies on NTDs) limits the evaluation of the consistency of specific negative findings across epidemiologic studies. Finally, there is no analytical observational study conducted on developing countries where farmers are exposed or likely to be exposed to higher internal doses of GLY because in tropical regions not to use routinely protective clothes and equipment when mixing, loading and spraying pesticides is the rule rather than an exception [34]. Along this line, human risk assessment would greatly benefit from a set of good quality epidemiologic studies, particularly from prospective cohort studies with quantitative estimations of exposure (e.g. by measuring urinary levels of GLY) before preconception and during pregnancy.

\begin{abstract}
Abbreviations
ADD/ADHD, attention deficit disorder / attention deficit hyperactivity disorder; AHS, agricultural health study; AMPA, aminomethylphosphonic acid; ANVISA, National agency for sanitary surveillance - Brazil; BIREME/BVS, Regional library of medicine/ health virtual library - Brazil; CFR, conditional fecundability ratio; ECLAMC, Latin American collaborative study on congenital malformations; EPSPS, enolpyruvylshikimate phosphate synthase; GLY, glyphosate; GM, genetically modified; IARC, International Agency for Research on Cancer; LILACS, Latin American and the Caribbean Literature on Health Sciences; MRCs, maximum residue concentrations; NTDs, neural tube defects; OFFHS, Ontario Farm Family Health Study; SGA, small-for-the gestational-age birth
\end{abstract}

\section{Acknowledgements}

The authors would like to thank their colleagues the Laboratory of Environmental Toxicology of the National School of Public Health - FIOCRUZ for their support and valuable contributions to this article.

\section{Funding}

JSA de A is a PhD student at National Institute of Health Quality ControlFIOCRUZ. FJRP and IFD were recipients of senior research fellowships from the Brazilian National Research Council (CNPq).

\section{Availability of data and materials}

Not applicable.

\section{Authors' contributions}

JSA de A, IFD and FJRP were involved in all stages of the study including the design, screening, review and analysis. JSA de A and FJRP conducted the literature search, screening and data extraction. FJRP and JSA de A drafted the manuscript. All authors read and approved the final manuscript.

\section{Competing interests}

The authors declare that they have no competing interests.

\section{Consent for publication}

Not applicable.

\section{Ethics approval and consent to participate}

Not applicable.

\section{Author details}

${ }^{1}$ National Institute for Health Quality Control, Oswaldo Cruz Foundation FIOCRUZ, Av. Brasil 4365, Rio de Janeiro, RJ 21040-900, Brazil. ${ }^{2}$ National School of Public Health, Oswaldo Cruz Foundation - FIOCRUZ, Av. Brasil 4036, EXCAM building, rooms 101-104, 913, Rio de Janeiro, RJ 21040-361, Brazil.

Received: 13 January 2016 Accepted: 26 May 2016

Published online: 06 June 2016

\section{References}

1. Williams GM, Kroes R, Munro IC. Safety evaluation and risk assessment of the herbicide Roundup and its active ingredient, glyphosate, for humans. Regul Toxicol Pharmacol. 2000;31(2 Pt 1):117-65.

2. Dallegrave E, Mantese FD, Coelho RS, Pereira JD, Dalsenter PR, Langeloh A The teratogenic potential of the herbicide glyphosate-Roundup in Wistar rats. Toxicol Lett. 2003;142(1-2):45-52.

3. Dallegrave E, Mantese FD, Oliveira RT, Andrade AJ, Dalsenter PR, Langeloh A. Pre- and postnatal toxicity of the commercial glyphosate formulation in Wistar rats. Arch Toxicol. 2007;81(9):665-73. 
4. Paganelli A, Gnazzo V, Acosta H, López SL, Carrasco AE. Glyphosate-based herbicides produce teratogenic effects on vertebrates by impairing retinoic acid signaling. Chem Res Toxicol. 2010;23(10):1586-95.

5. World Health Organization. Joint FAO/WHO Meeting on Pesticides Residues, Pesticide Residues in food, 2004, Part II, Toxicological Evaluation. Glyphosate 95-169, WHO/PCS/06.1. [http://www.inchem.org/documents/jmpr/ jmpmono/v2004pr01.pdf]

6. Guyton KZ, Loomis D, Grosse Y, El Ghissassi F, Benbrahim-Tallaa L, Guha N, Scoccianti C, Mattock H, Straif K. International Agency for Research on Cancer Monograph Working Group, IARC, Lyon, France. Carcinogenicity of tetrachlorvinphos, parathion, malathion, diazinon, and glyphosate. Lancet Oncol. 2015;16(5):490-1.

7. Carrasco A. Teratogenesis by glyphosate based herbicides and other pesticides. Relationship with the retinoic acid pathway. In: Brecling B, Verhoeven R, editors. GM-crop cultivation - Ecological Effects on a Landscape Scale. Theorie in der Ökologie 17. Frankfurt: Peter Lang; 2013.

8. Solomon KR, Anadón A, Carrasquilla G, Cerdeira AL, Marshall J, Sanin LH. Coca and poppy eradication in Colombia: environmental and human health assessment of aerially applied glyphosate. Rev Environ Contam Toxicol. 2007;190:43-125

9. Antoniou M, Habib M, Howard CV, Jennings RC, Leifert C, Nodari RO, Robinson C, Fagan J. Roundup and birth defects: Is the public being kept in the dark? Earth Open Source. 2011. [https://pt.scribd.com/ doc/ 57277946/ RoundupandBirthDefectsv5]. Acessed 15 Dez 2015.

10. Antoniou M, Habib MEM, Howard CV, Jennings RC, Leifert C, Nodari RO, Robinson CJ, Fagan J. Teratogenic Effects of Glyphosate-Based Herbicides: Divergence of Regulatory Decisions from Scientific Evidence. J Environ Anal Toxicol 2012: Suppl4. [http://dx.doi.org/10.4172/2161-0525.S4-006]

11. López SL, Aiassa D, Benítez-Leite S, Lajmanovich R, Manas F, Poletta G, Sánchez $\mathrm{N}$, Simoniello MF, Carrasco A. Pesticides used in South American GMO-Based agriculture: A review of their effects on humans and animal models. In: Fishbein JC, Heilman JM, editors. Advances in Molecular Toxicology Vol.6, Chapter 2. Amsterdam, The Netherlands: Elsevier; 2012. p. 41-75.

12. Samsel A, Seneff S. Glyphosate, pathways to modern diseases II: Celiac sprue and gluten intolerance. Interdiscip Toxicol. 2013;6(4):159-84.

13. García AM, Benavides FG, Fletcher T, Orts E. Paternal exposure to pesticides and congenital malformations. Scand J Work Environ Health. 1998;24(6):473-80.

14. Rull RP, Ritz B, Shaw GM. Neural tube defects and maternal residential proximity to agricultural pesticide applications. Am J Epidemiol. 2006;163(8):743-53.

15. Carmichael SL, Yang W, Roberts EM, Kegley SE, Wolff C, Guo L, Lammer EJ, English P, Shaw GM. Hypospadias and residential proximity to pesticide applications. Pediatrics. 2013;132(5):e1216-26.

16. Yang W, Carmichael SL, Roberts EM, Kegley SE, Padula AM, English PB, Shaw GM. Residential agricultural pesticide exposures and risk of neural tube defects and orofacial clefts among offspring in the San Joaquin Valley of California. Am J Epidemiol. 2014;179(6):740-8.

17. Shaw GM, Yang W, Roberts E, Kegley SE, Padula A, English PB, Carmichael SL. Early pregnancy agricultural pesticide exposures and risk of gastroschisis among offspring in the San Joaquin Valley of California. Birth Defects Res A Clin Mol Teratol. 2014;100(9):686-94.

18. Garry VF, Harkins ME, Erickson LL, Long-Simpson LK, Holland SE, Burroughs BL. Birth defects, season of conception, and sex of children born to pesticide applicators living in the Red River Valley of Minnesota, USA. Environ Health Perspect. 2002;110 Suppl 3:441-9.

19. Weselak M, Arbuckle TE, Wigle DT, Krewski D. In utero pesticide exposure and childhood morbidity. Environ Res. 2007;103(1):79-86.

20. Savitz DA, Arbuckle T, Kaczor D, Curtis KM. Male pesticide exposure and pregnancy outcome. Am J Epidemiol. 1997;146(12):1025-36.

21. Curtis KM, Savitz DA, Weinberg CR. Arbuckle TE The effect of pesticide exposure on time to pregnancy. Epidemiology. 1999;10(2):112-7.

22. Arbuckle TE, Lin Z, Mery LS. An exploratory analysis of the effect of pesticide exposure on the risk of spontaneous abortion in an Ontario farm population. Environ Health Perspect. 2001;109(8):851-7.

23. Sanin LH, Carrasquilla G, Solomon KR, Cole DC, Marshall EJ. Regional differences in time to pregnancy among fertile women from five Colombian regions with different use of glyphosate. J Toxicol Environ Health A. 2009;72(15-16):949-60.

24. Sathyanarayana S, Basso O, Karr CJ, Lozano P, Alavanja M, Sandler DP, Hoppin JA. Maternal pesticide use and birth weight in the agricultural health study. J Agromedicine. 2010;15(2):127-36.
25. Benítez-Leite S, Macchi ML, Acosta M. Malformaciones congenitas asociadas a agrotóxicos. Pediatr (Asunción). 2007;34(2):111-21.

26. Campaña H, Pawluk MS, López-Camelo JS. Prevalencia al nacimento de 27 anomalías congénitas selecionadas, en 7 regiones geográficas de la Argentina. Arch Argent Pediatr. 2010;108(5):409-17.

27. Water Pollutants Investigation Committee - First report (2010), Resistencia, Chaco, Argentina, 2010, 14 pp. [http://www.gmwatch.eu/files/Chaco_ Government_Report_English.pdf]

28. Vazques MA, Nota C. Report from the First National Meeting of Physicians in the crop-sprayed towns, Faculty of Medical Sciences, National University of Cordoba, August 27-8, 2010

29. Hill AB. The environment and disease: association or causation? Proc R Soc Med. 1965:58:295-300

30. Acquavella JF, Alexander BH, Mandel JS, Gustin C, Baker B, Chapman P, Bleeke M. Glyphosate biomonitoring for farmers and their families: results from the Farm Family Exposure Study. Environ Health Perspect. 2004;112(3):321-6.

31. Curwin BD, Hein MJ, Sanderson WT, Striley C, Heederik D, Kromhout H, Reynolds SJ, Alavanja MC. Urinary pesticide concentrations among children, mothers and fathers living in farm and non-farm households in lowa. Ann Occup Hyg. 2007;51(1):53-65.

32. Niemann L, Sieke C, Pfeil R, Solecki R. A critical review of glyphosate findings in human urine sampled and comparison with the exposure of operators and consumers. J Verbr Lebensm. 2015;10:3-12.

33. Aris A, Leblanc S. Maternal and fetal exposure to pesticides associated to genetically modified foods in Eastern Townships of Quebec. Can Reprod Toxicol. 2011;31(4):528-33.

34. Delgado IF, Paumgartten FJ. Pesticide use and poisoning among farmers from the county of Paty do Alferes, Rio de Janeiro, Brazil. Cad Saude Publica. 2004;20(1):180-6.

35. Pogoda JM, Preston-Martin S. Household pesticides and risk of pediatric brain tumors. Environ Health Perspect. 1997;105(11):1214-20.

36. Larsen SB, Joffe M, Bonde JP. Time to pregnancy and exposure to pesticides in Danish farmers. ASCLEPIOS Study Group. Occup Environ Med. 1998;55(4):278-83.

37. Nevison CD. A comparison of temporal trends in United States autism prevalence to trends in suspected environmental factors. Environ Health. 2014;13:73.

\section{Submit your next manuscript to BioMed Central and we will help you at every step:}

- We accept pre-submission inquiries

- Our selector tool helps you to find the most relevant journal

- We provide round the clock customer support

- Convenient online submission

- Thorough peer review

- Inclusion in PubMed and all major indexing services

- Maximum visibility for your research

Submit your manuscript at www.biomedcentral.com/submit 